\title{
Fuzzy Cognitive Maps Based Election Results Prediction System
}

\author{
Harmanjit Singh \\ Research Scholar, \\ Singhania University, \\ Rajasthan, INDIA
}

\author{
Dr. Gurdev Singh \\ Professor, Deptt of Information \& \\ Technology \\ Gurukul Vidyapeeth Institute of \\ Engineering \& Technology \\ Banur, Chandigarh
}

\author{
Nitin Bhatia \\ DAV College, Jalandhar \\ Punjab, INDIA
}

\begin{abstract}
Prediction and forecast are common words in the area of election. It can also be related with word "opinion poll". Although according to dictionary the meaning/definition of prediction is limited but practically prediction of election cannot be calculated under limited region. In general term, everybody is chipped with prediction. This relation may be direct or indirect. Prediction of weather, prediction about share market etc are few examples of prediction. Because of this, $n$ numbers of predictions can be calculated. Are these accurate as compared to actual result? This is still a question having no suitable answer. To predict the result from election is again a wide concept. Majority of tools and models are there which are used to predict the result but still the area of social science or political science is not up to that level where others are. Due to its vague and imprecision, it is quite complex. The objective of this research is to design and develop a simple GUI model based upon FCM which can be used to calculate the prediction in the term of winning chances of a candidate before the actual result. The concept of fuzzy logic along with fuzzy cognitive maps (FCM) is used to determine the relation between various input parameters. An accurate and simple GUI is designed for this proposed model.
\end{abstract}

\section{Keywords}

Fuzzy Cognitive Maps (FCM), Fuzzy Logic (FL), Election, Prediction, Vague, Concepts, GUI, Events and Result, Election Forecast

\section{Introduction}

Election means to select someone suitable from a group of people. Group can either be large or small. Again, it can be categorized into homogenous and heterogeneous. If there is election in a small group, in small organization or within a institution then this group is knows as homogeneous. But in election of country or state or city, this group is considered as heterogeneous. In a country election there are presidential elections, Parliamentary elections, Legislative assembly elections and elections for councilor in municipal areas. Moreover these elections play backbone role in the development of a small town/village. There is also a concept of elections the universities to select senate or syndicate. In India, cooperative banks have also same kind of elections to elect members and others. India is developing country and this country is divided into number of villages. Punjab a small state of India has more than 12,000 villages. Each and every village has their own selected committee (Gram Panchayat) which is responsible to develop the area under that village. Generally elections are there in those villages to help and to select suitable members for the committee from whole of the village. Apart from the above discussed sectors some religious organizations are also there which are based upon the elections.

Different electoral methods are adopted by different organizations to perform these elections. Election commission of India (ECI) is generally responsible to conduct elections in those fields which are directly related to the state government as well as center government. Like Parliamentary Elections, Legislative assembly Elections etc. Other organizations use their own techniques and resources to make these elections successful. The huge amount of money is also involved in these elections either directly or indirectly. This clearly indicates the power, value and importance of elections.
It doesn't mean that election is only a part political science or social science. Elections devote important part in Games like Cricket, Hockey, Basket ball etc. In other word, the selections of suitable from group of players for a match. Because of their own parameters this is generally known as "selection". Huge kind of reality shows are there on the media which are based upon the voting system from the spectators so that one can be selected or rejected from huge list of participants. Public opinion is the key factor which is used in these kinds of acts. But the question is how much it is relevant to find out the accurate result?

Election prediction is a way which is used to predict the result of an election before actual result. Different researches researched and discussed about different models and theories to provide the accuracy in this region i.e. prediction, forecast. Election prediction was normally based upon the public opinion. Still this parameter is currently not considered as out dated parameter. Some time one or two parameters are taken just to predict the result.

In this research a most popular concept named Fuzzy Logic along with FCM is used to design and develop a GUI model to calculate the percentage chances for winning candidate. The theory of fuzzy logic was given by Lotfi Zadeh in 1963 [1]. It is considered as superset of Boolean logic. It handles the concept of truth values that lie between the range of 0 and 1. It can also be used in both linear and non linear system for embedded control. It is simple method which helps to find out the results from vague and ambiguous data. It basically based upon rules and these rules helps to translate vague terms like yes or no into output [7]. Fuzzy logic has already been used in variety of sectors such as Artificial Intelligence, Multi Criteria Decision Making (MCDM), System Control, Medical Field, and Risk Prediction System in financial institution etc. The inference system of fuzzy (FIS) provides the output on the bases of numbers of input linguistic variables.

Every coin has two sides. Same way FIS has some disadvantages also. The main disadvantage with fuzzy inference system is that it does not describe the interdependence of input arguments. To find out such kind of interdependence there is a concept of Fuzzy Cognitive Map (FCM). It provides the strong and beneficial way to solve the above problem.

The rest of the sections of this research are designed as follows 2-Background, 3-Brief review about FCM, 4-Research Method, 4.1-Concepts Description, 4.2-FCM impact computation, 4.3-FCM Chart, 4.4-Weight Matrix, 5-Result Analysis, 6-Conclusion and Future Work and at last 7- References

\section{Background}

It was suggested by L. A. Zadeh that the theory of fuzzy set gives a good platform to identifying the meaning of propositions and dispositions [2]. In 1983, again Zadeh provided that fuzzy quantifier is engaged to sign up the collection of quantifiers in natural languages and uses of fuzzy set in the concepts of cardinality [3]. In 1993, Sugeno and Yasukawa recommended a fuzzy model which was useful in fuzzy clustering methods for structure identification [4]. In 1996, Zadeh explained the role of fuzzy logic in computing with words [5]. In 2003, Hayward and Davidson discussed lot of applications with the help of fuzzy logic [6]. In 2006, Shaout, B. King and Reisner declared a full fledge design and also implementation of real time fuzzy based system 


\section{Council for Innovative Research www.cirworld.com}

in a popular game named PAC-MAN [7]. In 2009, M. Barajas and B. Agrad provides the scope of fuzzy logic in the betterment of product family development process. For this research they used 14 fuzzy logic tools and 13 topics in the product family development process [8].

In 1999, Joao Paulo Carvalho and Jose A. B Tome gave rule based fuzzy cognitive maps and provide a way to implement fuzzy casual relations [9]. Fuzzy cognitive maps can also be used as a decision support tool was described by R. Sadiq, Y. Kleiner and B.B Rajani. They used this tool for the renewal of water mains [10]. In 2009, the FCM was used in medical decision support for the process of forecasting infectious diseases [11]. In 2010, the concept of FCM was used for evaluating the root reason for suicides using neutrosophic [12]. In 2008, fuzzy cognitive map was also used in banking industry to check the customer satisfaction level [13].

In 2007, Ke Meng, Rui Xia, Ting Ji and Feng Oian designed, and proved the method by applying radial basis functions (RBF) neural network in forecasting of Mackey-Glass chaos time series and also forecasting of electricity reference price of Queensland [14]. It is very difficult to build decision support systems (DSS) in political domain due to its heterogeneous factors. In 2011, the same kind of problem was solved by using FCM scheme to demonstrate the casual interrelationship and also for better reorganization about the factors [15]. In 2011, technical and social complexity of forest decision making based upon some computer based tools were discussed. Because of, it is more difficult for scientists and land-use managers to forecast the provision of goods and services into the long-term future [16]. In 2007, The FCM clustering method was also used to reduce sample data and it also proposed a method that can improve the forecasting accuracy [17].

\section{A Brief Review about Fuzzy Cognitive Maps}

In this part, the important and necessary information about the concepts of Fuzzy Cognitive Maps, are written in order to help readers of this research with the vital background they require.

The concept of Cognitive Maps was introduced and applied by a political scientist Axelrod in 1976 to rectify those desired states which are unclear [18]. These states are called as ill-structured problems. He developed signed digraphs design to extract the casual assertions of person with respect to certain area and then use them in order to find out the facts of alternative.FCM is a very simple and effective tool that is used in lots of applications like policies, business decisions, medical economics, project planning, robotics, expert systems etc.

He discussed case studies in the policy sector. It has only two basic types of elements. First then concepts and second is casual beliefs. In simple term they are knows as nodes \& arcs. Nodes describe the behavior of system and can be represented as variables. On the other side arcs are the relationships among the concepts either positive or negative. The positive relationship means that the change which effect variable undergoes is in the same direction and negative relationship means that the change which effect variable undergoes is in the opposite direction. Fig.1 shows the graphical representation of cognitive maps where variable $(\mathrm{P}, \mathrm{Q}, \mathrm{R}, \mathrm{S}, \mathrm{T})$ are represented as nodes and casual relationships as directed lines between concepts in term of signed digraph.

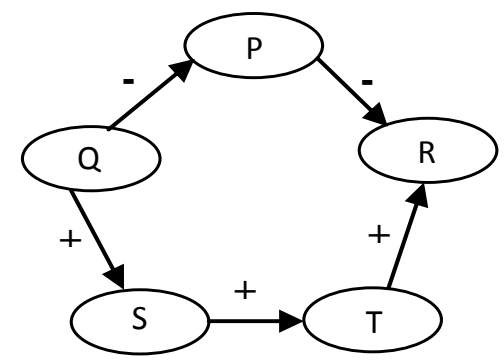

Fig. 1 An example of Cognitive Map (CM)
International Journal of Computers \& Technology

Volume 7 No. 1, May 2013, ISSN 2277-3061

Cognitive maps were designed and developed for knowledge bases construction, diagnosis of managerial problems, analysis to identify the effects of failure modes, how to model virtual world and their behavior, analysis of requirements, requirements for system specification, simulation, decision analysis and problem formulation [19].

Kosko introduced the concept of fuzzy cognitive maps (FCM). He also discussed about weighted cognitive maps [20]. It is assumed that FCM removes the issue of uncertainty and vagueness. Before the invention of FCM, the theory of fuzzy set was very popular and many researchers used this theory in their research areas. Fuzzy set were already used and implemented on many areas e.g decision making, expert system, image processing and recognition of patterns etc [21]. Again it is assumed that the terms like fuzzy data, fuzzy set, fuzzy rules and vagueness are consider like mathematical terms [22]. Degree of membership and membership functions are again the part of fuzzy sets.

Now the question is that why there is logic of linguistic variable why not real numbers in FCM. Initially it was proposed that some kind of specifications for fuzzy weights in an FCM [23]. One solution is that, an expert provides a real number from zero to one i.e. ( 0 , 1). This real number generates a connection for each and every relation. After this apply the method to calculate the average. But in reality, it is not so easy for expert(s) to provide a real number in interest to convey their feeling with honesty to the strength of relationships. Due to this reason and remove this ambiguity situation linguistic variables such as low < medium < high, etc. are used in place of mathematical real number.

Now FCM is a graph having directions with concepts like events etc. This is also called known as directed graph because it has nodes and edges also. This graph represents a normal connection / relationship between different concepts [24, 25].

Adjacency matrix is another way to describe a cognitive map. Because adjacency matrix clearly describes the image of relationship it there is any connection and in case of no relation it is blank. In other words, if there column in null then it means that there is no relation between these nodes. In following fig. 2, this concept is clearly described in the form of two dimensional matrix where some entries are null and others are filled with some + (positive) and - (negative) symbol $[26,13]$.

\begin{tabular}{|r|c|c|c|c|c|}
\hline & $\mathbf{P}$ & $\mathbf{Q}$ & $\mathbf{R}$ & $\mathbf{S}$ & $\mathbf{T}$ \\
\hline $\mathbf{P}$ & & & & & \\
\hline $\mathbf{Q}$ & - & & & + & \\
\hline $\mathbf{R}$ & & & & & \\
\hline $\mathbf{S}$ & & & & & + \\
\hline $\mathbf{T}$ & & & & & \\
\hline
\end{tabular}

Fig. 2 Adjacency Matrix Associated with a Cognitive Map

\section{Research Method}

The proposed fuzzy cognitive map based model in this paper considers the variables affecting the winning chances of a candidate in any kind of election and the relationships among them. Each mutual relationship includes one linguistic fuzzy weight which determines the prediction in term of percentage. This model includes 9 variables and 20 relationships. The whole process is divided into some steps to design and develop the FCM model. 


\section{Council for Innovative Research}

www.cirworld.com

In step first, the variables have been identified by studying and analyzing the material about elections from different constituencies'.

In step second, approximately 22 different variables were selected in starting phase and then 9 were finalized for the next round after debating with some experts.

In step third, a questioner was designed and filled from different groups of people. It was kept in mind that only those people will fill these questioners who are actually eligible for voting. After that, the data was analyzed for relevancy and 91 rules were finalized for Fuzzy Inference System (FIS). With the help of fuzzy toolbox in MATLAB software FIS was designed and analyzed the result to find out the percentage of winning chances as well as percentage of loosing chances of a candidate from an election

In step fourth, due the limitation of FIS the research was carried forward on FCM to get better result and find out the relationship among all the linguistic variables which were used in FIS also.

In the further section of this research paper, the complete explanation of the above steps and the approach has been discussed.

\subsection{Concepts Description}

The following table shows the description about all the ten concepts $\{\mathrm{C} 1, \mathrm{C} 2, \mathrm{C} 3, \mathrm{C} 4, \mathrm{C} 5, \mathrm{C} 6, \mathrm{C} 7, \mathrm{C} 8, \mathrm{C} 9$ and $\mathrm{C} 10\}$ which are used in this research. The table also shows the name of concepts, their symbol, their detail discussion and their values.

\begin{tabular}{|c|c|c|c|}
\hline $\begin{array}{l}\text { Concept } \\
\text { Symbol }\end{array}$ & Concepts & $\begin{array}{l}\text { Concepts } \\
\text { Description }\end{array}$ & $\begin{array}{l}\text { Linguistic } \\
\text { Variables }\end{array}$ \\
\hline C1 & $\begin{array}{l}\text { No of Years in } \\
\text { Active Politics }\end{array}$ & $\begin{array}{l}\text { Number of years in } \\
\text { active politics } \\
\text { means that whether } \\
\text { the candidate in } \\
\text { new for the voters } \\
\text { or he/she is already } \\
\text { famous in that } \\
\text { constituency }\end{array}$ & $\begin{array}{l}\text { Low, Medium, } \\
\text { High }\end{array}$ \\
\hline C2 & Popularity & $\begin{array}{l}\text { Popularity plays } \\
\text { vital role for a } \\
\text { candidate to win. } \\
\text { Candidate having } \\
\text { more interaction } \\
\text { with the people } \\
\text { means } \\
\text { popular. }\end{array}$ & $\begin{array}{l}\text { Low, Medium, } \\
\text { High }\end{array}$ \\
\hline C3 & Vote Bank & $\begin{array}{l}\text { It is directly related } \\
\text { with religious or } \\
\text { community factor. } \\
\text { It may possible that } \\
\text { in one particular } \\
\text { area there are more } \\
\text { numbers of voters } \\
\text { belong to particular } \\
\text { religion } \\
\text { community, then } \\
\text { they prefer to vote } \\
\text { for that candidate } \\
\text { who belongs to their } \\
\text { religion/community. }\end{array}$ & $\begin{array}{l}\text { Against, } \\
\text { No Impact, } \\
\text { In Favor }\end{array}$ \\
\hline C4 & $\begin{array}{l}\text { Performance in } \\
\text { Development }\end{array}$ & $\begin{array}{l}\text { It means that the } \\
\text { development } \\
\text { performance by that } \\
\text { candidate / party is } \\
\text { in the favor of }\end{array}$ & $\begin{array}{l}\text { Low, Medium, } \\
\text { High }\end{array}$ \\
\hline
\end{tabular}

International Journal of Computers \& Technology

Volume 7 No. 1, May 2013, ISSN 2277-3061

\begin{tabular}{|c|c|c|c|}
\hline & & voters or not. & \\
\hline C5 & $\begin{array}{l}\text { Inclination of } \\
\text { Voters towards } \\
\text { Party }\end{array}$ & $\begin{array}{l}\text { If a candidate } \\
\text { belongs to party } \\
\text { then it may possible } \\
\text { that image of that } \\
\text { party is very good } \\
\text { or vice versa in the } \\
\text { constituency. If it is } \\
\text { Good then there are } \\
\text { more number of } \\
\text { chance are there to } \\
\text { poll more numbers } \\
\text { of votes to that } \\
\text { party }\end{array}$ & $\begin{array}{l}\text { Low, Medium, } \\
\text { High }\end{array}$ \\
\hline C6 & $\begin{array}{l}\text { Currently in } \\
\text { Govt. }\end{array}$ & $\begin{array}{l}\text { Whether the } \\
\text { candidate belong to } \\
\text { opposition party or } \\
\text { ruling party. If a } \\
\text { party is ruling since } \\
\text { long time then they } \\
\text { have more words to } \\
\text { motivate their } \\
\text { voters during the } \\
\text { companion of their } \\
\text { candidate in term of } \\
\text { more number of } \\
\text { projects / schemes } \\
\text { etc. }\end{array}$ & Yes, No \\
\hline C7 & Major Issue & $\begin{array}{l}\text { It is possible that in } \\
\text { some states there } \\
\text { are some religious } \\
\text { or non religious } \\
\text { issues are there } \\
\text { which actually } \\
\text { affects on the } \\
\text { election either } \\
\text { directly or } \\
\text { indirectly. So all } \\
\text { these issues comes } \\
\text { under this heading } \\
\text { i.e. major issue. }\end{array}$ & $\begin{array}{l}\text { Against, No } \\
\text { Such Issue, } \\
\text { In Favor }\end{array}$ \\
\hline C8 & $\begin{array}{l}\text { Party/ } \\
\text { Independent }\end{array}$ & $\begin{array}{l}\text { Whether the } \\
\text { candidate belongs } \\
\text { to any party or not. } \\
\text { If not then this } \\
\text { Candidate is } \\
\text { considered as } \\
\text { independent } \\
\text { candidate. }\end{array}$ & $\begin{array}{l}\text { Party, } \\
\text { Independent }\end{array}$ \\
\hline C9 & Internal War & $\begin{array}{l}\text { It means that some } \\
\text { of the members of } \\
\text { the party do not like } \\
\text { that candidate } \\
\text { which is force ably } \\
\text { imposed in their } \\
\text { constituency by the } \\
\text { party. In these kind } \\
\text { of cases they } \\
\text { provides full hidden } \\
\text { support to the other } \\
\text { candidate }\end{array}$ & $\begin{array}{l}\text { No, Partially, } \\
\text { Fully }\end{array}$ \\
\hline C10 & $\begin{array}{l}\text { Winning } \\
\text { Chances }\end{array}$ & $\begin{array}{l}\text { How much } \\
\text { percentage chances } \\
\text { are there to win } \\
\text { from the election. }\end{array}$ & $\begin{array}{l}\text { Very Low, } \\
\text { Low, Medium, } \\
\text { High, Very } \\
\text { High }\end{array}$ \\
\hline
\end{tabular}

Table 1: Descriptions of Concepts

\subsection{FCM Impact Computation}

The selected nine concepts which are discussed in Table 1 are connected with each other. These concepts involve each other either 


\section{Council for Innovative Research}

www.cirworld.com

positively or negatively. These are knows as events. There are same numbers of FIS developed in MATLAB as number of events.

It is more important to finalize the impact type of a concept to another concept. Whether it strikes positively or negatively? After that with the help of all the FISs, (fuzzy inference system) level of impact was calculated and describe in Table 2.

\begin{tabular}{|c|c|c|c|}
\hline $\begin{array}{c}\text { Event } \\
\text { No }\end{array}$ & I/P Concept $\rightarrow$ O/P Concept & $\begin{array}{l}\text { Type of } \\
\text { Impact }\end{array}$ & $\begin{array}{l}\text { Level of } \\
\text { Impact }\end{array}$ \\
\hline 1 & NOYAP $* \rightarrow$ Winning Chances & $+\mathrm{Ve}$ & 0.777 \\
\hline 2 & NOYAP $* \rightarrow$ Popularity & $+\mathrm{Ve}$ & 0.584 \\
\hline 3 & NOYAP* $\rightarrow$ Vote Bank & $+\mathrm{Ve}$ & 0.553 \\
\hline 4 & NOYAP $* \rightarrow \mathrm{PID}^{* * *}$ & $+\mathrm{Ve}$ & 0.544 \\
\hline 5 & Popularity $\rightarrow$ Winning Chances & $+\mathrm{Ve}$ & 0.766 \\
\hline 6 & Popularity $\rightarrow$ Vote Bank & $+\mathrm{Ve}$ & 0.577 \\
\hline 7 & IOVTP $* * \rightarrow$ Winning Chances & $+\mathrm{Ve}$ & 0.824 \\
\hline 8 & IOVTP $* * \rightarrow$ Vote Bank & $+\mathrm{Ve}$ & 0.584 \\
\hline 9 & Currently in Govt $\rightarrow$ Winning Chance & $+\mathrm{Ve}$ & 0.816 \\
\hline 10 & Currently in Govt $\rightarrow$ Popularity & $+\mathrm{Ve}$ & 0.584 \\
\hline 11 & Currently in Govt $\rightarrow$ PID $* * *$ & $+\mathrm{Ve}$ & 0.553 \\
\hline 12 & $\mathrm{PID}^{* * *} \rightarrow$ Winning Chances & $+\mathrm{Ve}$ & 0.771 \\
\hline 13 & PID $* * * \rightarrow$ Vote Bank & $+\mathrm{Ve}$ & 0.619 \\
\hline 14 & PID*** $\rightarrow$ Popularity & $+\mathrm{Ve}$ & 0.584 \\
\hline 15 & Major Issue $\rightarrow$ Winning Chances & $+\mathrm{Ve}$ & 0.788 \\
\hline 16 & $\begin{array}{l}\text { Party/ Independent } \rightarrow \text { Winning } \\
\text { Chances }\end{array}$ & $+\mathrm{Ve}$ & 0.84 \\
\hline 17 & Vote Bank $\rightarrow$ Winning Chances & $+\mathrm{Ve}$ & 0.82 \\
\hline 18 & Internal War $\rightarrow$ Winning Chances & $-\mathrm{Ve}$ & 0.226 \\
\hline 19 & Internal War $\rightarrow$ Vote Bank & $-\mathrm{Ve}$ & 0.212 \\
\hline 20 & Internal War $\rightarrow$ Popularity & $-\mathrm{Ve}$ & 0.202 \\
\hline
\end{tabular}

Table 2: Relations between Concepts and their impact Level

*NOYAP $=$ No of Years in Active Politics

**IOVTP $=$ Inclinations of Voters towards Party

$* * * \mathrm{PID}=$ Performance in Development

For fuzzification and defuzzification, Mamdani algorithm and centroid are used respectively. An event number 5 is selected from Table 2 to more elaborate the Concept - Event relationship as an example.

Event 5: Popularity $\rightarrow$ Winning Chances: Variable popularity has three different values Low, Medium and High. For these different values, three different membership functions are used. Below is the description of all the three membership functions along with their mathematical formula.

zmf: Z-shaped built-in membership function (zmf) is used to define the variable Low. The weight is calculated by the following formula:

$$
f(x ; 0,0.5)=\left\{\begin{array}{c}
1, x \leq 0 \\
1-2\left(\frac{x-0}{0.5-0}\right)^{2}, 0 \leq x \leq \frac{0+0.5}{2} \\
2\left(\frac{x-0.5}{0.5-0}\right)^{2}, \frac{0+0.5}{2} \leq x \leq 0.5 \\
0, x \geq 0.5
\end{array}\right\}
$$

(Reproduced from [27])

gaussmf: Gaussian curve built-in membership function is used to define the variable Medium. The weight is calculated by the following formula:

$$
f x ; 0.2123,0.5=e^{\frac{-x-0.5^{2}}{20.2123^{2}}}
$$

International Journal of Computers \& Technology

Volume 7 No. 1, May 2013, ISSN 2277-3061

(Reproduced from [27])

smf: S-shaped built-in membership function is defined for variable High. The weight is calculated by the following formula:

$$
f(x ; 0.5,1)=\left\{\begin{array}{c}
0, x \leq 0.5 \\
2\left(\frac{x-0.5}{1-0.5}\right)^{2}, 0.5 \leq x \leq \frac{0.5+1}{2} \\
1-2\left(\frac{x-1}{1-0.5}\right)^{2}, \frac{0.5+1}{2} \leq x \leq 1 \\
1, x \geq 1
\end{array}\right\}
$$

(Reproduced from [27])

In Event 5, Popularity has a positive relation with Winning Chances. Winning Chances is considered as an output variable and it has five values: very low, low, medium, high and very high. All these 5 values are described by membership function trim.

trimf: Triangular-shaped built-in membership function is used to define all the values of output variables Winning Chances. The weight is calculated by the following formula:

$$
f(x ; a, b, c)=\left\{\begin{array}{cc}
0, & x \leq a \\
\frac{x-a}{b-a}, & a \leq x \leq b \\
\frac{c-x}{c-b}, & b \leq x \leq c \\
0, & c \leq x
\end{array}\right\}
$$

(Reproduced from [27])

\begin{tabular}{|l|c|c|c|}
\hline \multicolumn{1}{|c|}{ Parameters } & a & b & c \\
\hline Very Low & -0.25 & 0 & 0.25 \\
\hline Low & 0 & 0.25 & 0.5 \\
\hline Meduim & 0.25 & 0.5 & 0.75 \\
\hline High & 0.5 & 0.75 & 1 \\
\hline Very High & 0.75 & 1 & 1.25 \\
\hline
\end{tabular}

Table 3: Values of a, b \& c in trimf membership function

\subsection{Fuzzy Cognitive Map Chart}

The model of fuzzy cognitive map which is used in this research express various concepts along with the relationship between these concepts. 10 concepts are used in this proposed model. In other words, these are the factors which are used to find out the winning chances in this research. Some of these factors are for candidate point of view and others are of party point of view. Weighted arcs describe the relationship between concepts. Graphical representation of the above along with their degree or weight age is shown in Fig 3.

Ten (10) different concepts from $\mathrm{C} 1$ to $\mathrm{C} 10$ are used and also explained in Table 1. Different types of relationships are used in Fig. 3. These relationships describe the impact of one concept on other concept.

If the relationship is directly proportional then positive value on the arc is written. Directly proportional means that concept is directly effecting on the other. This effect may be either increasing or decreasing order. For example popularity of a candidate has direct relation with vote bank. Candidate who has high popularity means that he/she has more vote bank in his/her account and vice versa. 


\section{Council for Innovative Research \\ www.cirworld.com}

International Journal of Computers \& Technology

Volume 7 No. 1, May 2013, ISSN 2277-3061

If the relationship is inversely proportional then negative value on the arc is written. Inversely proportional means that concept is inversely effecting on the other. For example if there is an internal war between the workers of a party then changes for winning become less for that party candidate. In this case internal war is inversely proportional to wining chances.

No arc is there if there is no relation between two concepts. Even in weight matrix value zero $(0)$ is written. Zero represents no relation between concepts. For example there is no relation between internal war and major issue. So there is no arc.

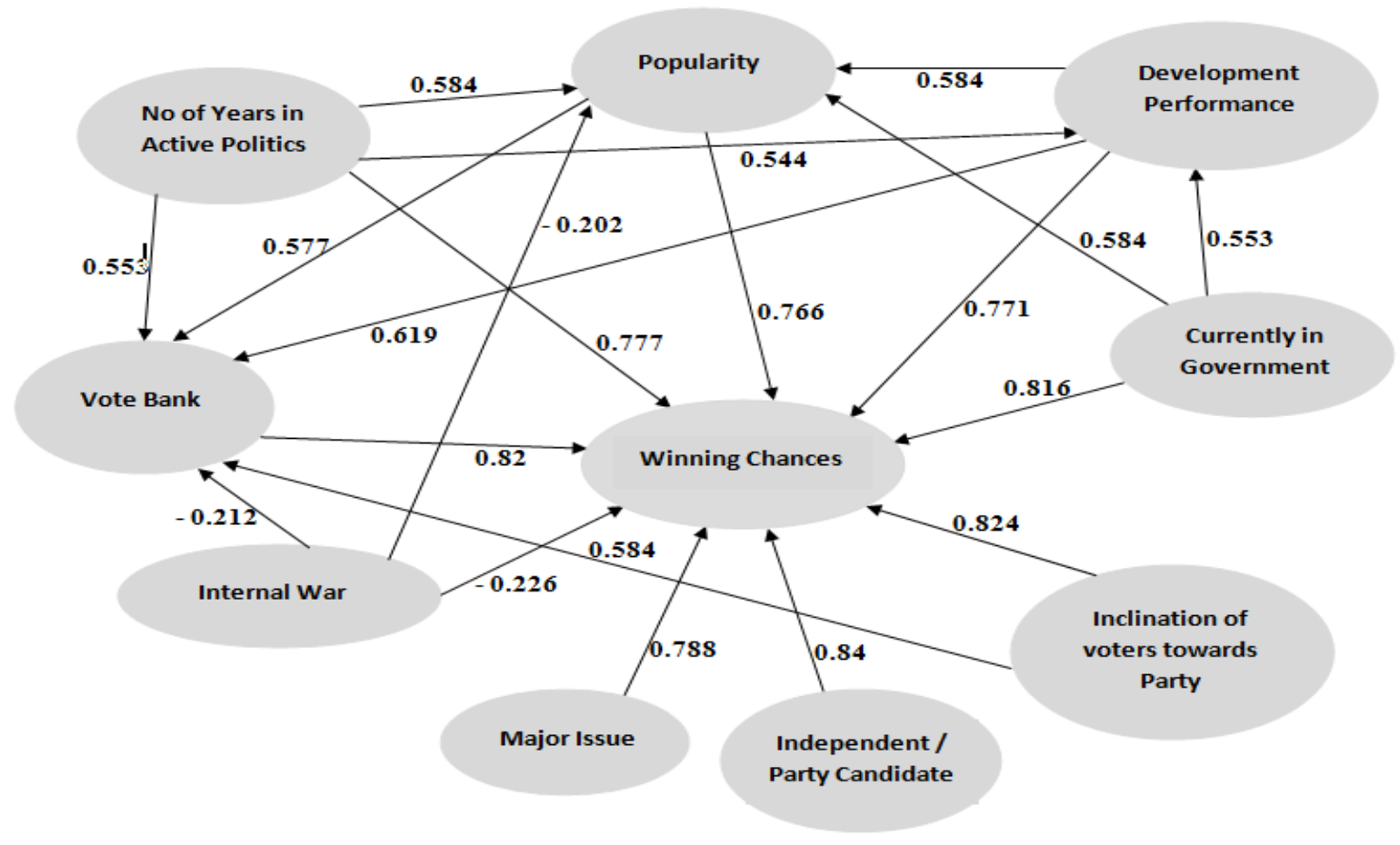

Fig. 3. FCM of Election Results Prediction System

\subsection{Weight Matrix}

Fig 3 describes the relations between two nodes. This relation can be positive, negative or no relation. This section provides the more clarity about the events, concepts and their dependencies. In this portion, a matrix is designed as show in Table 3. This matrix is called as weight matrix. Name of all the concepts are written as row heading and concepts symbol like $\mathrm{C} 1, \mathrm{C} 2$, etc are written as column heading. Each cell contains a value. These values are derived from MATLAB by executing FIS. Fuzzy inference system is designed and used for each and every event.
Weight matrix represents the weight-age between two concepts of FCM. The range of these values lies between [-1, 1]. Negative value represents the inverse relationship between concepts.

For example: 0.577 is written against the intersection of $\mathrm{C} 3$ row and C2 column. What does it mean? It means that popularity has a director impact on vote bank and the weight-age of this relationship is 0.577

\begin{tabular}{|l|c|c|c|c|c|c|c|c|c|c|c|}
\hline & & C1 & C2 & C3 & C4 & C5 & C6 & C7 & C8 & C9 & C10 \\
\hline $\begin{array}{l}\text { No of Years in Active } \\
\text { Politics }\end{array}$ & C1 & 0 & $\mathbf{0 . 5 8 4}$ & $\mathbf{0 . 5 5 3}$ & $\mathbf{0 . 5 4 4}$ & 0 & 0 & 0 & 0 & 0 & $\mathbf{0 . 7 7 7}$ \\
\hline Popularity & $\mathbf{C 2}$ & 0 & 0 & $\mathbf{0 . 5 7 7}$ & 0 & 0 & 0 & 0 & 0 & 0 & $\mathbf{0 . 7 6 6}$ \\
\hline Vote Bank & $\mathbf{C 3}$ & 0 & 0 & 0 & 0 & 0 & 0 & 0 & 0 & 0 & $\mathbf{0 . 8 2}$ \\
\hline $\begin{array}{l}\text { Performance in } \\
\text { Development }\end{array}$ & $\mathbf{C 4}$ & 0 & $\mathbf{0 . 5 8 4}$ & $\mathbf{0 . 6 1 9}$ & 0 & 0 & 0 & 0 & 0 & 0 & $\mathbf{0 . 7 7 1}$ \\
\hline
\end{tabular}




\begin{tabular}{|c|c|c|c|c|c|c|c|c|c|c|c|}
\hline $\begin{array}{l}\text { Inclination of Voters } \\
\text { towards Party }\end{array}$ & $\mathrm{C5}$ & 0 & 0 & 0 & 0.584 & 0 & 0 & 0 & 0 & 0 & 0.824 \\
\hline Currently in Govt. & C6 & 0 & 0.584 & 0 & 0.553 & 0 & 0 & 0 & 0 & 0 & 0.816 \\
\hline Major Issue & C7 & 0 & 0 & 0 & 0 & 0 & 0 & 0 & 0 & 0 & 0.788 \\
\hline Party/ Independent & C8 & 0 & 0 & 0 & 0 & 0 & 0 & 0 & 0 & 0 & 0.84 \\
\hline Internal War & C9 & 0 & -0.202 & -0.212 & 0 & 0 & 0 & 0 & 0 & 0 & -0.226 \\
\hline Winning Chances & C10 & 0 & 0 & 0 & 0 & 0 & 0 & 0 & 0 & 0 & 0 \\
\hline
\end{tabular}

Table 3: Weight Matrix

\section{Result Analysis}

This section describes about three different scenarios. Output is generated on the bases of different inputs in GUI of MATLAB under the concept of FCM.
Scenario 1: A candidate who is acting since long time in active politics also he belongs to ruling party. He is very popular in his constituency and also famous for development. Vote bank is also in his favor. He belongs to alliance. When all these inputs are given to prediction evaluator in MATLAB as shown in Fig 4 (a), following output is generated as shown in Fig 4 (b). This kind of candidate has $96 \%$ chances are there to win the election.

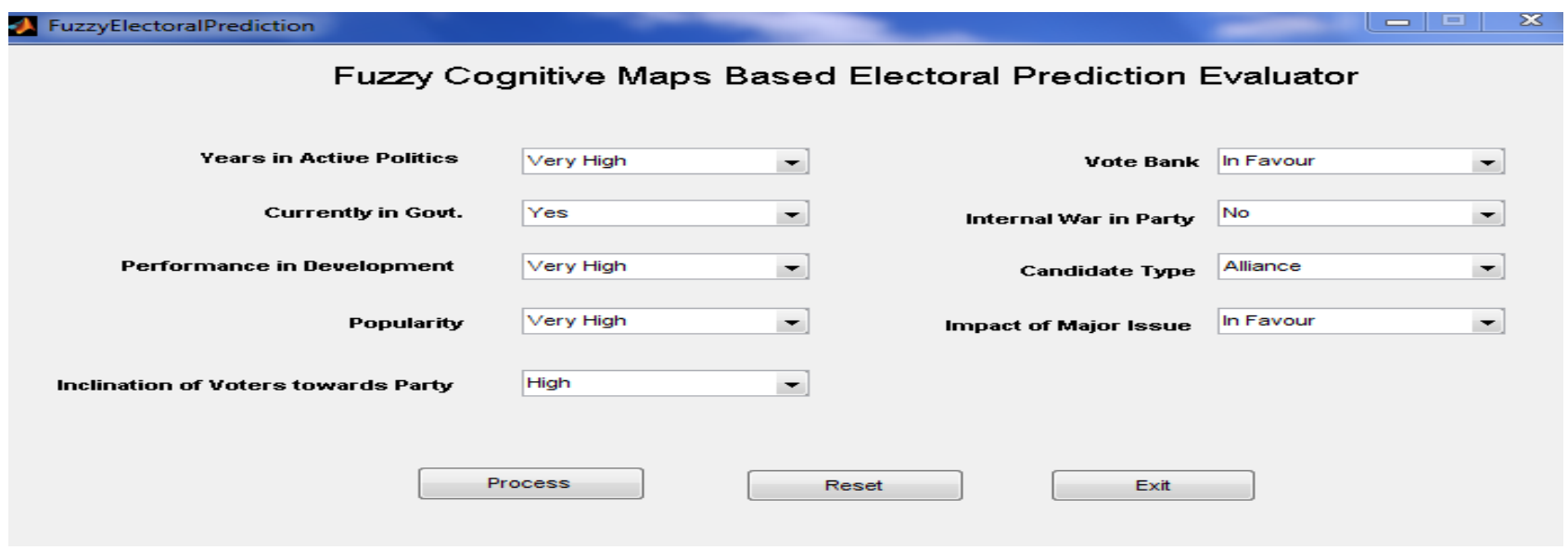

Fig 4 (a): Inputs Provided into Electoral Prediction Evaluator Based on Scenario 1

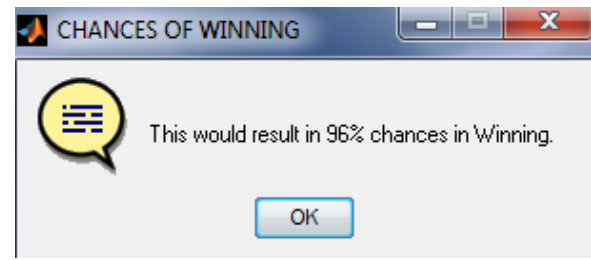

Fig 4 (b): Output of Scenario 1

Scenario 2: A candidate who is not acting since long time in active politics also he does not belongs to ruling party. Although he is very popular in his constituency with very high development performance but impact of vote bank is nil. On the other side, the impact of major issue is not in his favor. All these inputs are given to prediction evaluator in MATLAB to calculate winning chances as shown in Fig 5 (a). This type of candidate has less winning chances as compared to scenario 1 i.e $87 \%$ as shown in Fig 5 (b) 
Council for Innovative Research www.cirworld.com
International Journal of Computers \& Technology

Volume 7 No. 1, May 2013, ISSN 2277-3061

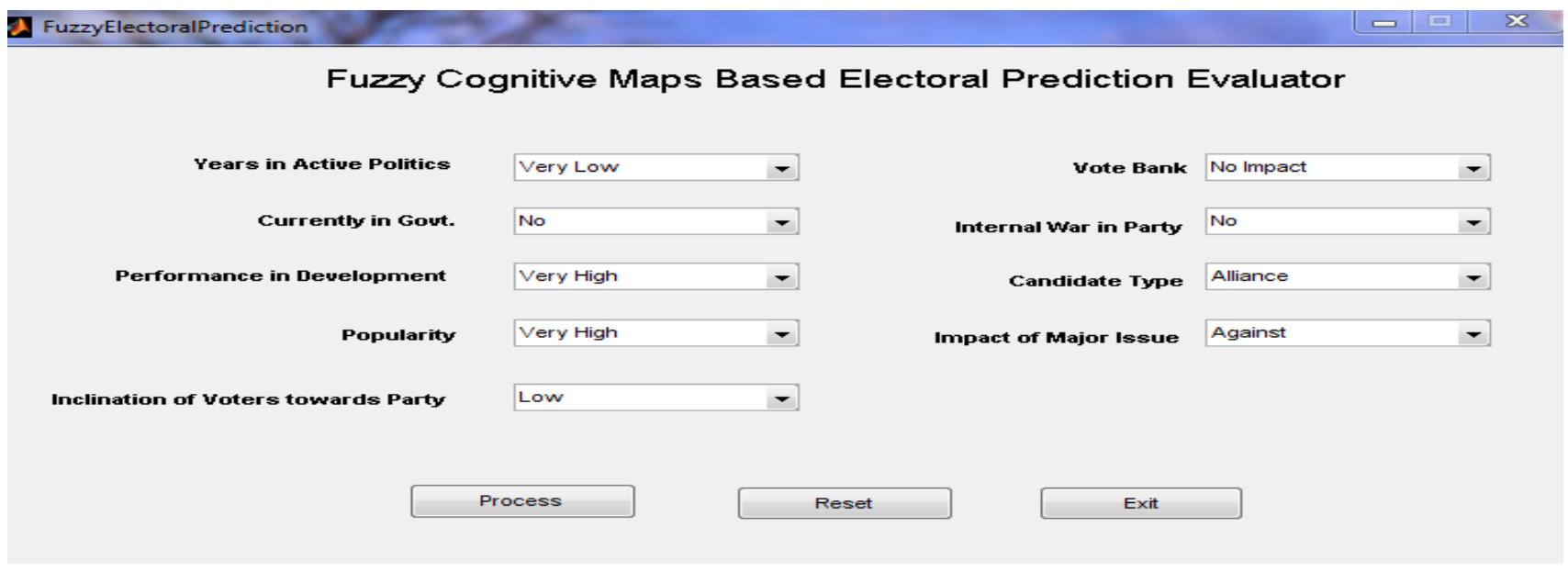

Fig 5 (a): Inputs Provided into Electoral Prediction Evaluator Based on Scenario 2

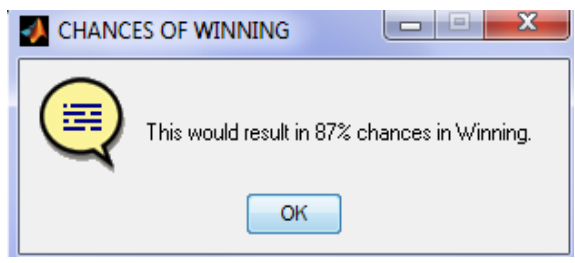

Fig 5 (b): Output of Scenario 2

Scenario 3: In this case, the value of parameter Years in Active Politics is Very Low, development performance and popularity of candidate is also very low. Candidate does not belong to any party or alliance. Vote bank is also not supporting for that candidate. Internal war is also acting with full pressure. The impact of major issue parameter has value is against. All these inputs are given to prediction evaluator in MATLAB to calculate winning chances as shown in Fig 6 (a). This type of candidate has only $26 \%$ winning chances are there as shown in Fig 6 (b) 


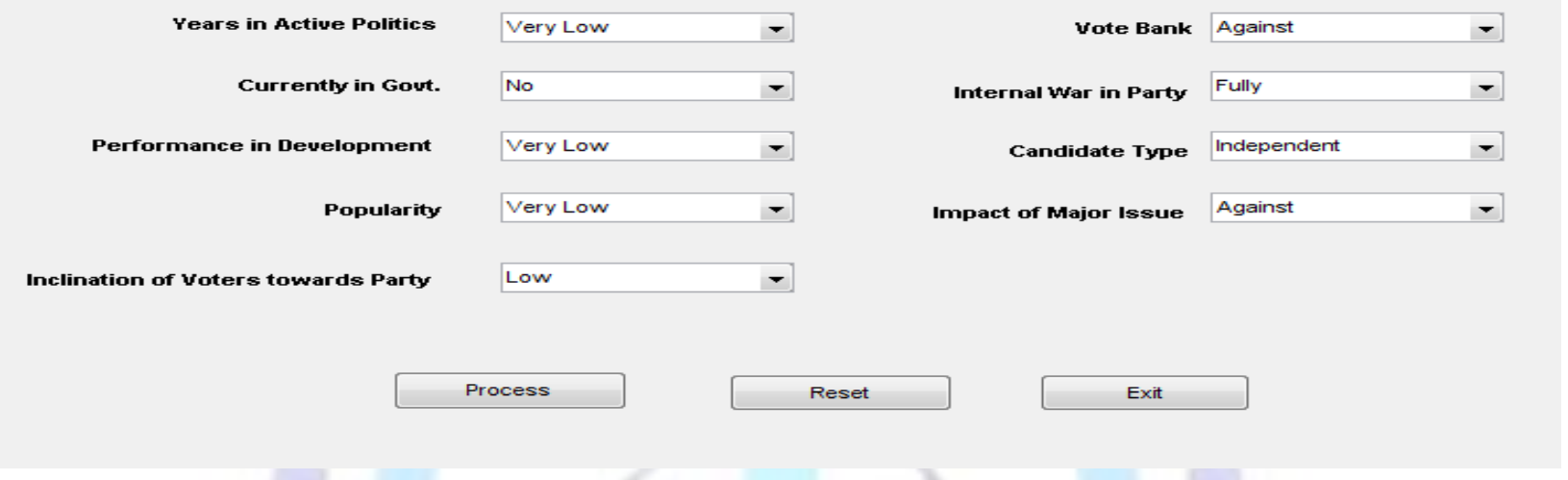

Fig 6 (a): Inputs Provided into Electoral Prediction Evaluator Based on Scenario 3

\section{Conclusion and Future Work}

This research work evaluates the winning chances of a candidate. Some factors / parameters are used for this proposed work. These factors are derived and discussed from experts in the area of political science. The purpose behind this research is to generate prediction for a candidate without using only public opinion. For this purpose, concept of fuzzy cognitive map is used. FCM chart is designed on the bases of above discussed parameters. The reason for this is because these parameters effects election. Weighted matrix is prepared from FCM chart that provides the more detail about concepts and their relations. At last some scenarios were selected randomly and generates the winning chances of a candidate

The future work of this research is that more number of parameters can be used to predict the result. Moreover these parameters can be changed as per the geographical area of constituency. Even the effect to time is also a responsible factor in election. New input parameters can be added or edited according to the time. Increment in sample size will also lead to give more accurate result.

\section{References}

[1] L. A. Zadeh, "Fuzzy sets, Informations and Control", 8, pp. 338-353, 1965.

[2] L. A. Zadeh, "Fuzzy Set Theoretic Approach to the Compositionality of Meaning: Propositions, Dispositions and Canonical Forms", N.I.S Foundation, Nijmegen Institute of Sematics.
[3] L. A. Zadeh, "A computational approach to fuzzy Quantifiers in natural languages", Comps. \& Maths with Applications, Vol. 9. No. 1, pp. 149-184, 1983.

[4] Michio Sugeno and Takahiro Yasukawa, "A Fuzzy-logicbased approach to qualitative modeling", IEEE Transactions on Fuzzy Systems, Vol. 1, No. 1, February 1993.

[5] L. A. Zadeh, "Fuzzy logic - Computing with words", IEEE Transactions on Fuzzy Systems, Vol. 4, No. 2, May 1996.

[6] Gordon Hayward and Valerie Davidson, "Fuzzy Logic applications”, Analyst, 2003, 128, pp. 1304-1306.

[7] Adnan Shaout, Brady King, and Luke Reisner, "Real time game design of Pac-man using Fuzzy logic", The International Arab Journal of Information Technology, Vol 3, No. 4, October 2006.

[8] Marco Barajas and Bruno Agard, "The use of Fuzzy Logic in product family development-Literature review and opportunities", CIRRELT, 2009.

[9] João Paulo Carvalho and José A. B Tome, "Rule Based Fuzzy Cognitive Maps: Fuzzy Causal Relations”, 1999.

[10] R. Sadiq, Y. Kleiner and B.B. Rajani, "Fuzzy cognitive maps for decision support to maintain water quality in ageing water 


\section{Council for Innovative Research} www.cirworld.com
International Journal of Computers \& Technology Volume 7 No. 1, May 2013, ISSN 2277-3061 mains", Proceedings Of The 4th International Conference On Decision Making In Urban And Civil Engineering, pp 1-10.

[11] Elpiniki I. Papageorgiou, Nikolaos I. Papandrianos, Georgia Karagianni, George C. Kyriazopoulos and Dimitrios Sfyras, "A Fuzzy Cognitive Map based tool for prediction of infectious diseases", IEEE International Conference Fuzzy Systems, FUZZ-IEEE 2009, pp. 2094 - 2099.

[12] P. Thiruppathi, N.Saivaraju and K.S. Ravichandran, "A Solution to Control Suicides using Combined Overlap Block Fuzzy Cognitive Maps", International Journal of Computer Applications (0975 - 8887) Vol. 11- No.2, December 2010.

[13] S. M. Reza Nasserzadeh, M. Hamed Jafarzadeh, Taha Mansouri, Babak Sohrabi, "Customer Satisfaction Fuzzy Cognitive Map in Banking Industry", Communications of the International Business Information Management Association. Vol. 2, 2008, pp. 151-162.

[14] Ke Meng, Rui Xia, Ting Ji, Feng Oian, "Electricity Reference Price Forecasting with Fuzzy C-means and Immune Algorithm", Congress on Evolutionary Computation (CEC 2007), IEEE, pp. 2337-2343.

[15] Sammera Al Shayji, Nahla El Zant El Kadhi, Zidong Wang, "Fuzzy Cognitive Map theory for the Political Domain", Proceedings of the Federated Conference on Computer Science and Information Systems, IEEE, 2011, pp. 179-186.

[16] Anna Lawrence, Amy Stewart, "SUSTAINABLE FORESTRY DECISIONS: ON THE INTERFACE BETWEEN TECHNOLOGY AND PARTICIPATION", Mathematical and Computational Forestry \& Natural-Resource Sciences (MCFNS), Vol. 3, Issue 1, 2011, pp. 42-52.

[17] Yongkang Zheng, Weirong Chen, Chaohua Dai, Shengyong Ye, "Short-term Load Forecasting Based on FCM and Complex Gaussian Wavelet SVM", Advances in Intelligent Systems Research, International Conference on Intelligent Systems and Knowledge Engineering (ISKE), October 2007.

[18] Axelrod R. "Structure of Decision: The Cognitive Maps of Political Elites", Princeton University Press, Princeton, NJ, 1976.

[19] Kardaras D, Karakostas B, "The use of fuzzy cognitive maps to simulate the information systems strategic planning process", Information and Software Technology 41, pp.197210, 1999 .

[20] Kosko. B, "Fuzzy cognitive maps", International Journal on Man-Machine Studies 24, 65-75, 1986.

[21] Zimmermann H.J. "Fuzzy Set Theory and its Applications", Kluwer Academic Publishers, Dordrecht, 1991.

[22] Editorial E.J., "Fuzzy Models- what are they, and why", IEEE Transactions on Fuzzy Systems, 1993.

[23] Taber R. "Knowledge processing with fuzzy cognitive maps", Expert Systems with Applications, 83-87, 1991.
[24] P. Thiruppathi, N.Saivaraju and K.S. Ravichandran, "A Solution to Control Suicides using Combined Overlap Block Fuzzy Cognitive Maps", International Journal of Computer Applications (0975 - 8887), Vol 11- No.2, December 2010.

[25] W. B. Vasantha Kandasamy and Florentin Smarandache, "Fuzzy Cognitive Maps and Neutrosophic Cognitive Maps", Book published in 2003.

[26] Bueno S., Salmeron J.L., "Fuzzy modeling Enterprise Resource Planning tool selection", Computer Standards \& Interfaces, Volume 30, Issue 3, Pages 137-147, 2008.

[27] Gursharan Singh, Nitin Bhatia., and Swatantar Singh, "Fuzzy Cognitive Maps Based Cricket Player Performance Evaluator", International Journal of Enterprise Computing and Business Systems, Vol. 1, Issue 2, 2011.

[28] Harmanjit Singh, Dr. Gurdev Singh, Nitin Bhatia, "Election Results Prediction System based on Fuzzy Logic", International Journal of Computer Application (IJCA), Volume 53, Issue 9, September 2012.

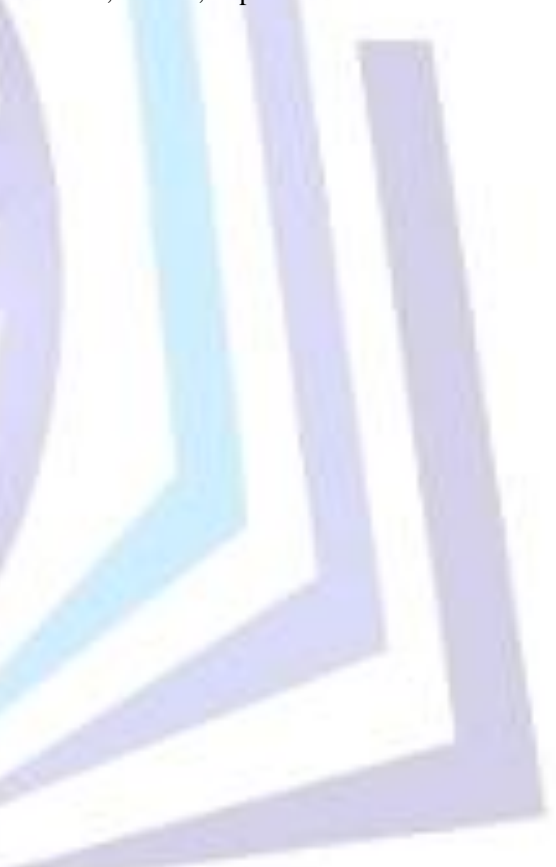




\section{Council for Innovative Research www.cirworld.com}

\section{Authors Profile}

Harmanjit Singh received his Graduate degree in Arts in 1998 and Master's degree in Information Technology in 2007 from Punjab Technical University, Jalandhar, India along with Master's degree in Computer Application in 2008 from Punjab Technical University, Jalandhar, India. He is working as Assistant Professor in Department of Computer Science, Punjab College of Technical Education (PCTE), Baddowal, Ludhiana. He is also pursuing Ph.D from Singhania University, Rajasthan, India. He has more than eight research papers to his credit. His areas of interest are fuzzy logic, graph theory, google adsense and SEO. He is also associated with various international journals as reviewer. His email id is professorhskanwer@yahoo.com.

Dr Gurdev Singh received his Graduate degree in Arts in 2000 and Master's degree in Math in 2002 from Guru Nanak Dev University, Amritsar, India. He is working as Professor in Department of Information Technology, Gurukul Vidyapeeth Institute of Engineering \& Technology, Banur, Chandigarh. He has completed his Ph.D in 2010 in CSE. He has more than thirty research papers to his credit. His areas of interest are cloud computing, software metrics and fuzzy logic. He is also associated with various international journals as member of editorial team. His email id is singh.gndu@gmail.com.

Nitin Bhatia received his Graduate degree in Science in 1998 and Master's degree in Computer Application in 2001 from Guru Nanak Dev University, Amritsar, India. He is working as Lecturer in Department of Computer Science, DAV College, Jalandhar. He is also pursuing Ph.D from Punjabi University, Patiala, India. He has more than twenty five research papers to his credit. His areas of interest are pattern recognition, computer vision and fuzzy logic. He is also associated with various international journals as reviewer. His email id is n_bhatia78@yahoo.com. 